\title{
Safety and efficacy of 4-phenylbut-3-en-2-one and benzophenone belonging to chemical group 21 when used as flavouring compounds for all animal species
}

\author{
EFSA Panel on Additives and Products or Substances used in Animal Feed (FEEDAP), \\ Vasileios Bampidis, Giovanna Azimonti, Maria de Lourdes Bastos, Henrik Christensen, \\ Mojca Kos Durjava, Maryline Kouba, Marta López-Alonso, Secundino López Puente, \\ Francesca Marcon, Baltasar Mayo, Alena Pechová, Mariana Petkova, Fernando Ramos, \\ Yolanda Sanz, Roberto Edoardo Villa, Ruud Woutersen, Paul Brantom, Andrew Chesson, \\ Johannes Westendorf, Lucilla Gregoretti, Paola Manini and Birgit Dusemund
}

\begin{abstract}
Following a request from the European Commission, the EFSA Panel on Additives and Products or Substances used in Animal Feed (FEEDAP) was asked to deliver a scientific opinion on the safety and efficacy of 4-phenylbut-3-en-2-one [07.024] and benzophenone [07.032] belonging to chemical group 21 , when used as feed flavourings for all animal species. They are currently authorised for use as flavours in food. The use of 4-phenyl-3-butene-2-one [07.024] is safe at the proposed normal use levels of $1 \mathrm{mg} / \mathrm{kg}$ complete feed for all animal species. Benzophenone [07.032] is safe at the proposed normal use levels of $1 \mathrm{mg} / \mathrm{kg}$ complete feed for all animal species except chicken for fattening, laying hens and piglets, for which the calculated safe concentration in feed is $0.5 \mathrm{mg} / \mathrm{kg}$. No safety concern would arise for the consumer from the use of 4-phenyl-3-butene-2-one [07.024] and benzophenone [07.032] as feed flavourings. In the absence of studies to assess the safety for the user, the FEEDAP Panel cannot conclude on the safety for users when handling the additives. The use of 4-phenyl-3butene-2-one [07.024] and benzophenone [07.032] in animal feed at the maximum safe use level in feed is also considered safe for the environment. Since the compounds under assessment are used in food as flavourings and their function in feed is essentially the same as that in food, no further demonstration of efficacy is necessary.
\end{abstract}

(c) 2020 European Food Safety Authority. EFSA Journal published by John Wiley and Sons Ltd on behalf of European Food Safety Authority.

Keywords: sensory additives, feed flavourings, aromatic ketones, chemical group 21, safety

Requestor: European Commission

Question number: EFSA-Q-2016-00453

Correspondence: feedap@efsa.europa.eu 
Panel members: Giovanna Azimonti, Vasileios Bampidis, Maria de Lourdes Bastos, Henrik Christensen, Birgit Dusemund, Maryline Kouba, Mojca Kos Durjava, Marta López-Alonso, Secundino López Puente, Francesca Marcon, Baltasar Mayo, Alena Pechová, Mariana Petkova, Fernando Ramos, Yolanda Sanz, Roberto Edoardo Villa and Ruud Woutersen.

Acknowledgements: The EFSA FEEDAP Panel (EFSA Panel on Additives and Products or Substances used in Animal Feed) wishes to thank the following for the support provided to this scientific output: Angelica Amaduzzi, Jaume Galobart and Fabiola Pizzo.

Suggested citation: EFSA FEEDAP Panel (EFSA Panel on Additives and Products or Substances used in Animal Feed), Bampidis V, Azimonti G, Bastos ML, Christensen H, Kos Durjava M, Kouba M, LópezAlonso M, López Puente S, Marcon F, Mayo B, Pechová A, Petkova M, Ramos F, Sanz Y, Villa RE, Woutersen R, Brantom P, Chesson A, Westendorf J, Gregoretti L, Manini P and Dusemund B, 2020. Scientific Opinion on the safety and efficacy of 4-phenylbut-3-en-2-one and benzophenone belonging to chemical group 21 when used as flavouring compounds for all animal species. EFSA Journal 2020;18 (2):6017, 12 pp. https://doi.org/10.2903/j.efsa.2020.6017

ISSN: $1831-4732$

(C) 2020 European Food Safety Authority. EFSA Journal published by John Wiley and Sons Ltd on behalf of European Food Safety Authority.

This is an open access article under the terms of the Creative Commons Attribution-NoDerivs License, which permits use and distribution in any medium, provided the original work is properly cited and no modifications or adaptations are made.

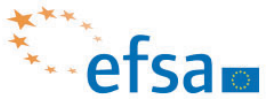

The EFSA Journal is a publication of the European Food Safety Authority, an agency of the European Union.

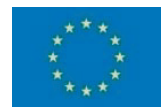




\section{Table of contents}

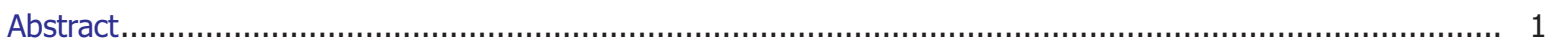

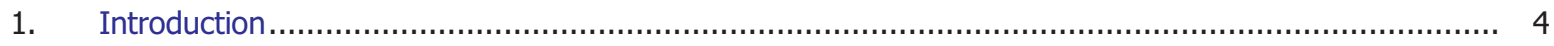

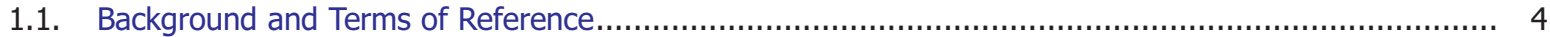

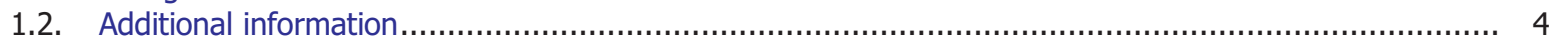

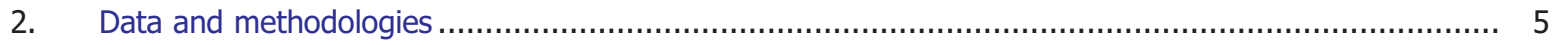

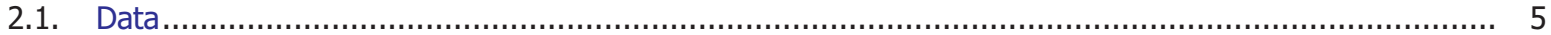

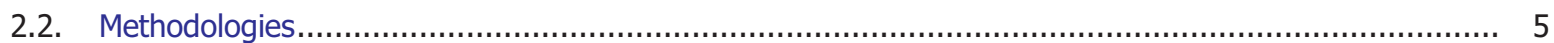

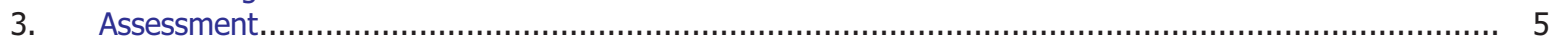

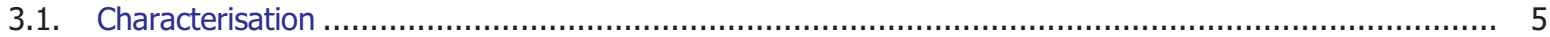

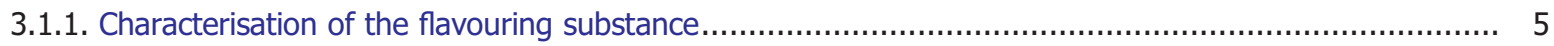

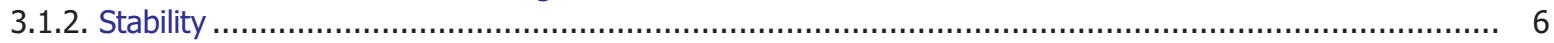

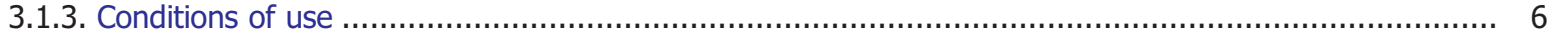

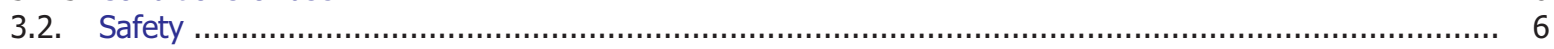

3.2.1. Absorption, distribution, metabolism and excretion (ADME) and residue studies ............................... 7

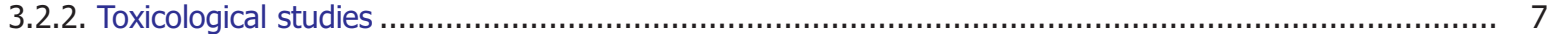

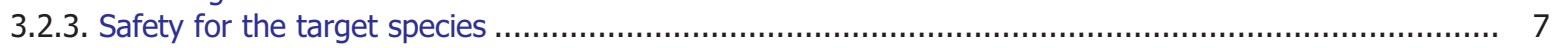

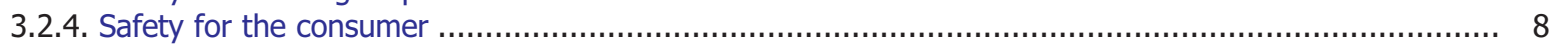

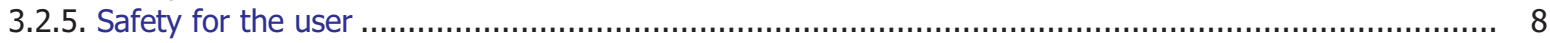

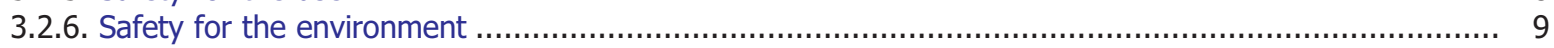

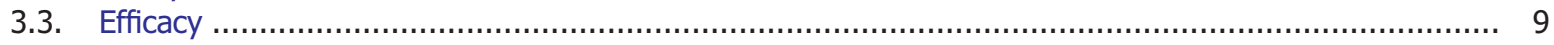

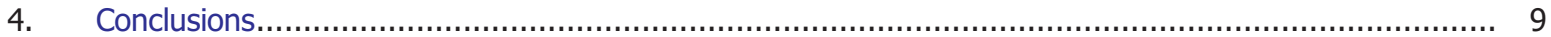

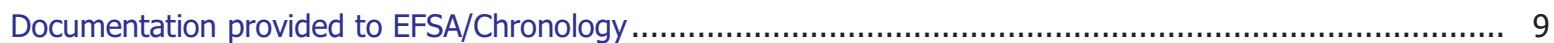

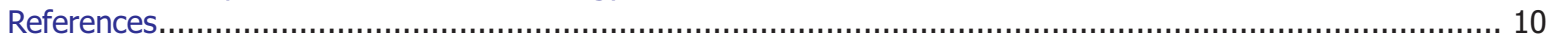

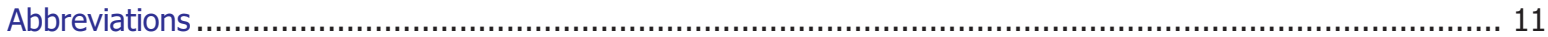

Annex A - Executive Summary of the Evaluation Report of the European Union Reference Laboratory for

Feed Additives on the Method(s) of Analysis for Aromatic ketones, secondary alcohols and related esters....... 12 


\section{Introduction}

\subsection{Background and Terms of Reference}

Regulation (EC) No $1831 / 2003^{1}$ establishes the rules governing the Community authorisation of additives for use in animal nutrition. In particular, Article 4(1) of that Regulation lays down that any person seeking authorisation for a feed additive or for a new use of a feed additive shall submit an application in accordance with Article 7, in addition, Article 10(2) of that Regulation also specifies that for existing products within the meaning of Article 10(1), an application shall be submitted in accordance with Article 7, within a maximum of 7 years after the entry into force of this Regulation.

The European Commission received a request from Feed Flavourings Authorisation Consortium European Economic Interest Grouping (FFAC EEIG) ${ }^{2}$ for authorisation of 10 substances (1-phenylethan-1-ol, acetophenone, vanillyl acetone, 4-methylacetophenone, 4-phenylbut-3-en-2-one, 4-(4-methoxyphenyl)butan-2-one, benzophenone, 4-methoxyacetophenone, 4-(p-hydroxyphenyl)- butan-2-one (hereafter referred as 4-(4-hydroxyphenyl)-butan-2-one) and 1-phenethyl acetate) belonging to chemical group (CG) 21, when used as feed additives for all animal species (category: sensory additives; functional group: flavourings). CG 21 for flavouring substances is defined in Commission Regulation (EC) No 1565/2000 3 as 'aromatic ketones, secondary alcohols and related esters.' During the course of the assessment, this application was split and the present opinion covers only two out of the 10 substances under application (see Section 1.2).

According to Article 7(1) of Regulation (EC) No 1831/2003, the Commission forwarded the applications to the European Food Safety Authority (EFSA) as applications under Article 4(1) (authorisation of a feed additive or new use of a feed additive) and under Article 10(2) (re-evaluation of an authorised feed additive). During the course of the assessment, the applicant withdrew the application for the use of chemically defined flavourings in water for drinking. ${ }^{4}$ EFSA received directly from the applicant the technical dossier in support of this application. The particulars and documents in support of this application were considered valid by EFSA as of 20 September 2010.

According to Article 8 of that Regulation, EFSA, after verifying the particulars and documents submitted by the applicant, shall undertake an assessment in order to determine whether the feed additives comply with the conditions laid down in Article 5 .

EFSA shall deliver an opinion on the safety for the target animals, consumer, user and the environment and on the efficacy of 4-phenylbut-3-en-2-one (EU Flavour Information System (FLAVIS) number) [07.024] and benzophenone [07.032], when used under the proposed conditions of use (see Section 3.1.3).

\subsection{Additional information}

The initial application on CG 21 concerned 10 compounds, intended to be used as feed flavourings for all animal species. The European Food Safety Authority (EFSA) Panel on Additives and Products or Substances used in Animal Feed (FEEDAP) has already delivered an opinion on eight of the 10 compounds included in CG 21 (EFSA FEEDAP Panel, 2016).

The remaining compounds 4-phenylbut-3-en-2-one [07.024] and benzophenone [07.032] were excluded from the previous opinion because at that time the assessment for use in food as flavouring was not complete. For 4-phenylbut-3-en-2-one [07.024], the EFSA Panel on Food Contact Materials, Enzymes, Flavourings and Processing Aids (CEF) had requested additional toxicity data to complete the assessment (EFSA, 2008a; EFSA CEF Panel 2014). The EFSA Panel on Food Additives and Flavourings (EFSA FAF Panel) has delivered an opinion and concluded that the genotoxicity concerns for 4phenylbut-3-en-2-one [07.024] could be ruled out (EFSA FAF Panel, 2019). EFSA issued an opinion on the safety of benzophenone [07.032] as food flavour (EFSA, 2008a) and another opinion on the toxicological evaluation of benzophenone as food contact material (EFSA, 2009). Subsequently, the

\footnotetext{
${ }^{1}$ Regulation (EC) No 1831/2003 of the European Parliament and of the Council of 22 September 2003 on additives for use in animal nutrition. OJ L 268, 18.10.2003, p. 29.

2 On 13/3/2013, EFSA was informed by the applicant that FFAC EEIG was liquidated on 19/12/2012 and their rights as applicant were transferred to FEFANA Asbl (EU Association of Specialty Feed Ingredients and their Mixtures), Avenue Louise 130A, Box 1, 1050 Brussels, Belgium.

${ }^{3}$ Commission Regulation (EC) No 1565/2000 of 18 July 2000 laying down the measures necessary for the adoption of an evaluation programme in application of Regulation (EC) No 2232/96 of the European Parliament and of the Council. OJ L 180, 19.7.2000, p. 8.

${ }^{4}$ On 10 March 2016, EFSA was informed by the European Commission on the withdrawal of the application for re-authorisation of chemically defined flavourings - use in water.
} 
Joint FAO/WHO Expert Committee on Food Additives (JECFA) (WHO, 2011) and IARC (2013) evaluated the same substance based on studies that were not considered in EFSA opinions. Consequently, the European Commission requested that the existing literature on the safety of this flavouring substance should be reviewed. Following this review, the EFSA CEF Panel concluded that there is no safety concern for benzophenone when used as a flavouring substance (EFSA CEF Panel, 2017).

The compounds under assessment 4-phenylbut-3-en-2-one [07.024] and benzophenone [07.032] are currently listed in the European Union database of flavouring substances ${ }^{5}$ and in the European Union Register of Feed Additives, respectively, and thus authorised for use in food and feed in the European Union. They have not been previously assessed by EFSA as feed additives.

\section{Data and methodologies}

\subsection{Data}

The present assessment is based on data submitted by the applicant in the form of technical dossiers ${ }^{6}$ in support of the authorisation request for the use of the compounds under assessment as feed additives.

The FEEDAP Panel used the data provided by the applicant together with data from other sources, such as previous risk assessments by EFSA or other expert bodies, peer-reviewed scientific papers and experts' knowledge, to deliver the present output.

EFSA has verified the European Union Reference Laboratory (EURL) report as it relates to the methods used for the control of flavourings from Chemical group 21 - saturated and unsaturated aliphatic secondary alcohol/ketones/esters with esters containing secondary alcohols. No aromatic or heteroaromatic moiety as a component of an ester or ketal - in animal feed. The Executive Summary of the EURL report can be found in Annex A. ${ }^{7}$

\subsection{Methodologies}

The approach followed by the FEEDAP Panel to assess the safety and the efficacy of 'aromatic ketones, secondary alcohols and related esters' is in line with the principles laid down in Regulation (EC) No 429/2008 and the relevant guidance documents ${ }^{9}$ : Guidance for the preparation of dossiers for sensory additives (EFSA FEEDAP Panel, 2012a), Technical Guidance for assessing the safety of feed additives for the environment (EFSA 2008b), Guidance for the preparation of dossiers for additives already authorised for use in food (EFSA FEEDAP Panel, 2012b), Guidance for establishing the safety of additives for the consumer (EFSA FEEDAP Panel, 2012c), Guidance on studies concerning the safety of use of the additive for users/workers (EFSA FEEDAP Panel, 2012d).

\section{Assessment}

The additives under assessment, 4-phenylbut-3-en-2-one [07.024] and benzophenone [07.032], belong to chemical group 21 - 'aromatic ketones, secondary alcohols and related esters as feed additives' and are intended for use as sensory additives (functional group: flavouring compounds) in feed for all animal species.

\subsection{Characterisation}

\subsubsection{Characterisation of the flavouring substance}

The molecular structure of the additives under application is shown in Figure 1 and their physicochemical characteristics in Table 1.

\footnotetext{
${ }^{5}$ Commission Implementing Regulation (EU) No 872/2012 of 1 October 2012 adopting the list of flavouring substances provided for by Regulation (EC) No 2232/96 of the European Parliament and of the Council, introducing it in Annex I to Regulation (EC) No 1334/2008 of the European Parliament and of the Council and repealing Commission Regulation (EC) No 1565/2000 and Commission Decision 1999/217/EC. OJ L 267, 2.10.2012, p. 1.

${ }^{6}$ FEED dossier reference: FAD-2010-0417.

7 The full report is available on the EURL website: https://ec.europa.eu/jrc/sites/default/files/FinRep-FAD-2010-0074.pdf

${ }^{8}$ Commission Regulation (EC) No 429/2008 of 25 April 2008 on detailed rules for the implementation of Regulation (EC) No $1831 / 2003$ of the European Parliament and of the Council as regards the preparation and the presentation of applications and the assessment and the authorisation of feed additives. OJ L 133, 22.5.2008, p. 1.

9 The Guidance documents in force in 2011-2012 were exceptionally applied to the present assessment to ensure consistency in the assessment of feed flavourings (re-evaluation of authorised feed additives).
} 


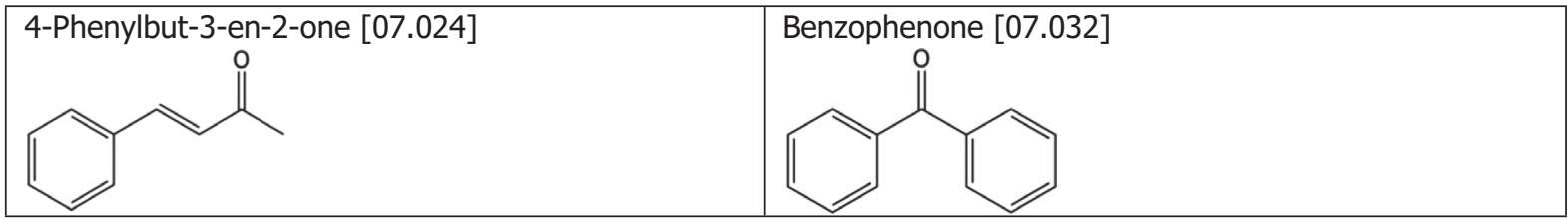

Figure 1: Molecular structures, EU register names and [FLAVIS numbers] of the flavouring compounds under assessment

Table 1: Chemical Abstracts Service (CAS) and FLAVIS numbers and some characteristics of the chemically defined flavourings under assessment

\begin{tabular}{l|c|c|c|c|c|c}
\hline EU register name & CAS no & Flavis No & $\begin{array}{l}\text { Molecular } \\
\text { formula }\end{array}$ & $\begin{array}{c}\text { Molecular } \\
\text { weight }\end{array}$ & $\begin{array}{l}\text { Physical } \\
\text { state }\end{array}$ & Log Kow \\
\hline 4-Phenylbut-3-en-2-one & $122-57-6$ & 07.024 & $\mathrm{C}_{10} \mathrm{H}_{10} \mathrm{O}$ & 146.19 & Solid & 2.07 \\
\hline Benzophenone & $119-61-9$ & 07.032 & $\mathrm{C}_{13} \mathrm{H}_{10} \mathrm{O}$ & 182.22 & Solid & 3.18 \\
\hline
\end{tabular}

The compounds under consideration are produced by chemical synthesis and the typical routes of synthesis are described for each compound. ${ }^{10}$

Data were provided on the batch to batch variation in five batches of the additives. ${ }^{11}$ The content of the active substance for each compound exceeded in all batches the minimum content reported in the JECFA specifications (FAO, 2006).

Table 2: Identity of the substances and data on purity

\begin{tabular}{l|c|c|c|c}
\hline \multirow{2}{*}{ EU register name } & \multirow{2}{*}{ Flavis no } & $\begin{array}{c}\text { JECFA specification } \\
\text { minimum \%(a) }\end{array}$ & Average & Range \\
\hline 4-Phenylbut-3-en-2-one & 07.024 & 97 & 99.6 & $99.5-99.8$ \\
\hline Benzophenone & 07.032 & 98 & 99.6 & $99.0-100$ \\
\hline
\end{tabular}

(a): FAO (2006).

Potential contaminants are considered as part of the product specification and are monitored as part of the Hazard Analysis and Critical Control Point (HACCP) procedure applied by all consortium members. The parameters considered include residual solvents, heavy metals and other undesirable substances. However, no evidence of compliance was provided for these parameters.

\subsubsection{Stability}

The minimum shelf-life of 4-phenylbut-3-en-2-one [07.024] and benzophenone [07.032] is claimed to be 21 and 24 months, respectively, when stored in closed containers under recommended conditions. ${ }^{12}$ This assessment is made on the basis of compliance with the original specification over this storage period.

\subsubsection{Conditions of use}

4-Phenylbut-3-en-2-one [07.024] and benzophenone [07.032] are intended for use in feed for all animal species without withdrawal period. For the compounds under assessment, the applicant proposes a normal use level of $1 \mathrm{mg} / \mathrm{kg}$ feed and a high use level of $5 \mathrm{mg} / \mathrm{kg}$ feed.

\subsection{Safety}

The assessment of safety is based on the high use level proposed by the applicant $(5 \mathrm{mg} / \mathrm{kg}$ complete feed).

The compounds under assessment have been recently evaluated by EFSA as food flavourings (EFSA CEF Panel, 2017; EFSA FAF Panel, 2019), and no safety concerns were identified.

\footnotetext{
10 Technical dossiers FAD-2010-0417.

11 Technical dossier FAD-2010-0417/Section II/Annex 2.1 and Supplementary information May 2011.

12 Technical dossier FAD-2010-0417/Supplementary information May 2011.
} 


\subsubsection{Absorption, distribution, metabolism and excretion (ADME) and residue studies}

Information on the metabolism of 4-phenylbut-3-en-2-one [07.024] and benzophenone [07.032] in laboratory animals has been described in a previous assessment by the Joint FAO/WHO Expert Committee on Food Additives (JECFA, WHO, 2002).

Experiments with $\left[{ }^{14} \mathrm{C}\right.$-ring](E)-4-phenyl-3-buten-2-one given to rats as single oral dose showed a rapid absorption and excretion of the compound mainly via the kidneys. No accumulation of radioactivity occurred in the tissues. The main metabolic pathway was the oxidation of the side chain to result in phenylacetic acid, which was conjugated with glycine and excreted via urine. Less than $10 \%$ of the parent compound was also transformed to benzoic acid, which was also excreted in urine as glycine conjugate (hippuric acid). Other metabolites formed in small amounts (5\% or less) were the glutathione conjugate of the parent ketone and the secondary alcohol resulting from reduction of the ketone. The parent ketone could not be observed in the excreta (Sauer et al., 1997a, as quoted by WHO, 2002). Similar results were obtained in mice with the difference of the excretion of about $8 \%$ of the parent ketone in the urine (Sauer et al., 1997b, as quoted by WHO, 2002).

Studies in rats and rabbits showed a complete absorption of benzophenone and a rapid excretion of its metabolites via the kidneys. The absorption rate of the compound in mice after oral application was only half of that observed in rats. The main metabolic pathway was the reduction of the ketone to the secondary alcohol (benzhydrol), which was conjugated with glucuronic acid and excreted via urine (Dix et al., 1997a,b as quoted by WHO, 2002). About $1 \%$ of the compound was p-hydroxylated at one aromatic ring and excreted as glucuronide. ${ }^{13}$

Studies of metabolism of compounds belonging to CG 21 in animals other than rodents are lacking in the scientific literature. ${ }^{14}$ However, the enzymes involved in the biotransformation pathways of these compounds are present in all target species (reviewed in EFSA FEEDAP Panel, 2016). Therefore, foodproducing animals, including fish and birds, as well as non-food producing animals can also be assumed to have the ability to metabolise and excrete the flavourings under assessment.

\subsubsection{Toxicological studies}

Subchronic studies or other repeated-dose studies were not made available by the applicant for 4phenylbut-3-en-2-one [07.024].

The toxicological profile of benzophenone [07.032] has been recently reviewed by the EFSA CEF Panel, which confirmed the conservative approach taken by EFSA in 2009 to derive a tolerable daily intake (TDI) of $0.03 \mathrm{mg} / \mathrm{kg}$ body weight (bw) per day when used as a food contact material (EFSA, 2009; EFSA CEF Panel, 2017). This was based on the lower 95\% confidence limits of the benchmark dose for a $10 \%$ effect $\left(B_{M D L}\right)$ of $3.1 \mathrm{mg} / \mathrm{kg}$ bw pw day derived for non-neoplastic kidney effects in male rats in a 2-year study (NTP, 2006). The FEEDAP Panel agrees with the assessment of the EFSA CEF Panel and considers this $\mathrm{BMDL}_{10}$ as a suitable point of departure to derive safe concentrations in feed.

\subsubsection{Safety for the target species}

The maximum feed concentration which can be considered safe for the target animals can be derived from the lowest No Observed Adverse Effect Level (NOAEL) or BMDL ${ }_{10}$ identified, if suitable data are available (EFSA FEEDAP Panel, 2012a).

Toxicological data derived from a chronic study were available for benzophenone [07.032] (see Section 3.2.2) for which a $\mathrm{BMDL}_{10}$ of $3.1 \mathrm{mg} / \mathrm{kg}$ bw per day was derived. Applying an uncertainty factor (UF) of 100 to the $\mathrm{BMDL}_{10}$, the maximum safe intake for the target species was derived for the compounds following the EFSA Guidance for sensory additives (EFSA FEEDAP Panel, 2012a), and thus, the maximum safe feed concentration was calculated (Table 3).

\footnotetext{
13 FAD-2010-0417/Section III/Annex 3.18 HDBS 2010.

${ }^{14}$ Technical dossiers FAD-2010-0417/Section III.
} 
Table 3: Maximum safe concentration in feed for different target animals for benzophenone [07.032]

\begin{tabular}{l|c|c|c|c}
\hline & $\begin{array}{c}\text { Body weight } \\
(\mathbf{k g})\end{array}$ & $\begin{array}{c}\text { Feed intake } \\
(\mathbf{g} / \mathbf{d a y})^{(\mathbf{a})}\end{array}$ & $\begin{array}{c}\text { Maximum safe } \\
\text { intake } \mathbf{( m g / d a y )}\end{array}$ & $\begin{array}{c}\text { Maximum safe concentration } \\
\text { (mg/kg feed) }\end{array}$ \\
\hline Salmonids & 2 & 40 & 0.06 & 1.6 \\
\hline Veal calves (milk replacer) & 100 & 2,000 & 3.10 & 1.6 \\
\hline Cattle for fattening & 400 & 8,000 & 12.4 & 1.4 \\
\hline Dairy cows & 650 & 20,000 & 20.2 & 0.9 \\
\hline Piglets & 20 & 1,000 & 0.62 & 0.6 \\
\hline Pigs for fattening & 100 & 3,000 & 3.10 & 1.0 \\
\hline Sows & 200 & 6,000 & 6.20 & 1.0 \\
\hline Chickens for fattening & 2 & 120 & 0.06 & 0.5 \\
\hline Laying hens & 2 & 120 & 0.06 & 0.5 \\
\hline Turkeys for fattening & 12 & 400 & 0.37 & 0.9 \\
\hline Dogs & 15 & 250 & 0.47 & 1.6 \\
\hline Cats & 3 & 60 & 0.09 & 1.3 \\
\hline
\end{tabular}

(a): Complete feed with $88 \%$ DM, except milk replacer for veal calves $(94.5 \% \mathrm{DM})$, and for cattle for fattening, dairy cows, dogs and cats for which the values are DM intake.

(b): Complete feed containing $88 \%$ DM, milk replacer $94.5 \%$ DM.

Since an individual reliable NOAEL could not be found for 4-phenylbut-3-en-2-one [07.024], the threshold of toxicological concern (TTC) approach was followed to derive the maximum safe feed concentration as described in the guidance on sensory additives (EFSA FEEDAP Panel, 2012a). ${ }^{15}$ For this Cramer class I compound, the calculated safe use level is $1.5 \mathrm{mg} / \mathrm{kg}$ complete feed for cattle, salmonids and non-food producing animals and $1.0 \mathrm{mg} / \mathrm{kg}$ complete feed for pigs and poultry.

\section{Conclusions on safety for the target species}

The FEEDAP Panel concludes that

- 4-phenylbut-3-en-2-one [07.024] is safe at the proposed normal use levels of $1 \mathrm{mg} / \mathrm{kg}$ complete feed for all animal species,

- benzophenone [07.032] is safe at the proposed normal use levels of $1 \mathrm{mg} / \mathrm{kg}$ complete feed for all animal species except chicken for fattening, laying hens and piglets, for which the calculated safe concentration in feed is $0.5 \mathrm{mg} / \mathrm{kg}$ complete feed.

\subsubsection{Safety for the consumer}

The safety for the consumer of the compounds used as food flavour has been already assessed by JECFA (WHO, 2001, 2002) and EFSA (EFSA CEF Panel, 2014, EFSA FAF Panel, 2019). The compound is currently authorised in the EU as food flavourings without limitations. ${ }^{5}$

Although deposition and residue studies of the compound in farm animals are not available, the FEEDAP Panel considers that the use of 4-phenyl-3-butene-2-one [07.024] and benzophenone [07.032] in animal feed would not appreciably increase the human exposure to these compounds. This is based on the low use levels to be applied in feed and the expected extensive metabolism and excretion in target animals (see Section 3.2.1). Consequently, no safety concern would arise for the consumer from the use of the compounds up to the highest levels considered safe for target animals.

\subsubsection{Safety for the user}

No specific data to assess the safety for the user were submitted. Therefore, the FEEDAP Panel cannot conclude on the safety for users when handling the additive. The applicant produced a safety data sheet ${ }^{16}$ for 4-phenyl-3-butene-2-one [07.024] and benzophenone [07.032] where hazards for users have been identified.

\footnotetext{
${ }^{15}$ When the TTC approach is applied, target species are divided into two groups, one including poultry and pigs and another one including cattle, salmonids and non-food producing animals. For these two groups and for a Cramer class I compound, the calculated safe use levels were rounded to 1.0 and $1.5 \mathrm{mg} / \mathrm{kg}$ complete feed, respectively.

16 Technical dossier FAD-2010-0417/Section II/Annex II.3. Hazards for skin and eye contact and for respiratory exposure are recognised for 4-phenyl-3-butene-2-one [07.024] and benzophenone [07.032]. 4-Phenyl-3-butene-2-one [07.024] is also reported to be a skin sensitiser.
} 


\subsubsection{Safety for the environment}

The compounds under assessment are naturally occurring in the environment ${ }^{17}$ or expected to be extensively metabolised in the animal (see Section 3.2.1) or subsequently in the environment. Consequently, their use in animal nutrition at the concentrations in feed considered safe for the target species is also considered safe for the environment.

\subsection{Efficacy}

Since the compounds under assessment are used in food as flavourings, and their function in feed is essentially the same as that in food, no further demonstration of efficacy is necessary.

\section{Conclusions}

The use of 4-phenyl-3-butene-2-one [07.024] is safe at the proposed normal use level of $1 \mathrm{mg} / \mathrm{kg}$ complete feed for all animal species. Benzophenone [07.032] is safe at the proposed normal use level of $1 \mathrm{mg} / \mathrm{kg}$ complete feed for all animal species except chickens for fattening, laying hens and piglets, for which the calculated safe concentration in feed is $0.5 \mathrm{mg} / \mathrm{kg}$ feed.

No safety concern would arise for the consumer from the use of 4-phenyl-3-butene-2-one [07.024] and benzophenone [07.032] as feed flavourings.

In the absence of studies to assess the safety for the user, the FEEDAP Panel cannot conclude on the safety for users when handling the additives.

The use of 4-phenyl-3-butene-2-one [07.024] and benzophenone [07.032] in animal feed at the maximum safe use level in feed is also considered safe for the environment.

Since the compounds under assessment are used in food as flavourings and their function in feed is essentially the same as that in food, no further demonstration of efficacy is necessary.

\section{Documentation provided to EFSA/Chronology}

\begin{tabular}{|c|c|}
\hline Date & Event \\
\hline $27 / 07 / 2010$ & $\begin{array}{l}\text { Dossier received by EFSA. Chemically defined flavourings from Chemical Group } 21 \text { - Aromatic } \\
\text { ketones, secondary alcohols and related esters: 4-phenylbut-3-en-2-one [07.024] and } \\
\text { benzophenone [07.032] (CDG 21). Submitted by FEFANA Asbl/Feed Flavourings Authorisation } \\
\text { Consortium European Economic Interest Grouping (FFAC EEIG) }\end{array}$ \\
\hline 09/08/2010 & Reception mandate from the European Commission \\
\hline 20/07/2010 & Application validated by EFSA - Start of the scientific assessment \\
\hline $30 / 09 / 2010$ & $\begin{array}{l}\text { Request of supplementary information to the applicant in line with Article } 8(1)(2) \text { of Regulation } \\
\text { (EC) No } 1831 / 2003 \text { - Scientific assessment suspended. Issues: characterisation, safety for target } \\
\text { species, safety for the consumer, safety for the user and efficacy }\end{array}$ \\
\hline $28 / 01 / 2011$ & Reception of the Evaluation report of the European Union Reference Laboratory for Feed Additives \\
\hline $21 / 12 / 2010$ & Comments received from Member States \\
\hline $11 / 01 / 2012$ & Reception of supplementary information from the applicant - Scientific assessment re-started \\
\hline 04/06/2012 & $\begin{array}{l}\text { Request of supplementary/complementary information to the applicant in line with Article } 8(1)(2) \\
\text { of Regulation (EC) No 1831/2003 (addendum) - Scientific assessment remains suspended Issues: } \\
\text { safety for the consumer }\end{array}$ \\
\hline $11 / 03 / 2013$ & $\begin{array}{l}\text { Request of supplementary/complementary information to the applicant in line with Article } 8(1)(2) \\
\text { of Regulation (EC) No } 1831 / 2003 \text { (addendum) - Scientific assessment remains suspended Issues: } \\
\text { safety for the environment }\end{array}$ \\
\hline $10 / 03 / 2016$ & Partial withdrawal from EC: use in water (Art. (4)) \\
\hline 02/03/2016 & $\begin{array}{l}\text { The applicant was informed that the application was split into two separate questions with two } \\
\text { different EFSA-Q-numbers. The initial EFSA-Q-2010-01041 was assigned to the } 8 \text { compounds for } \\
\text { which EFSA has completed the evaluation as food flavours, whereas the new EFSA-Q-2016-00453 } \\
\text { was assigned to the } 2 \text { compounds, for which the assessment was pending }\end{array}$ \\
\hline 26/01/2020 & Reception of supplementary information from the applicant - Scientific assessment re-started \\
\hline $28 / 01 / 2020$ & Opinion adopted by the FEEDAP Panel. End of the Scientific assessment \\
\hline
\end{tabular}
17 Technical dossier FAD-2010-0412/Supplementary information June 2011. Data taken from the TNO database Volatile
Compounds in Food ver. 14.1; Burdock (2009). 


\section{References}

Burdock GA, 2009. Fenaroli's handbook of flavor ingredients, 6th Edition. CRC Press, Boca Raton, FL, USA.

EFSA (European Food Safety Authority), 2008a. Scientific Opinion of the Panel on Food Additives, Flavourings, Processing Aids and Materials in contact with food (AFC) on a request from the Commission on Flavouring Group Evaluation 69 (FGE.69): consideration of aromatic substituted secondary alcohol, ketones and related esters evaluated by JECFA (57th meeting) structurally related to aromatic ketones from chemical group 21 evaluated by EFSA in FGE.16 (2006). EFSA Journal 2008;6(11):869, 35 pp. https://doi.org/doi:10.2903/j.efsa. 2008.869

EFSA (European Food Safety Authority), 2008b. Technical Guidance of the Scientific Panel on Additives and Products or Substances used in Animal Feed (FEEDAP) for assessing the safety of feed additives for the environment. EFSA Journal 2008;6(10):842, 28 pp. https://doi.org/doi:10.2903/j.efsa.2008.842

EFSA (European Food Safety Authority), 2009. Scientific Opinion of EFSA prepared by the Panel on food contact materials, enzymes, flavourings and processing aids (CEF) on Toxicological evaluation of benzophenone. EFSA Journal 2009;7(6):1104, 30 pp. https://doi.org/10.2903/j.efsa.2009.1104

EFSA CEF Panel (EFSA Panel on Food Contact Materials, Enzymes, Flavourings and Processing Aids), 2014. Scientific Opinion on Flavouring Group Evaluation 215 (FGE.215): seven $\alpha, \beta$-Unsaturated Cinnamyl Ketones from subgroup 3.2 of FGE.19. EFSA Journal 2014;12(4):3623, 23 pp. https://doi.org/doi:10.2903/j.efsa.2014. 3623

EFSA CEF Panel (EFSA Panel on Food Contact Materials, Enzymes, Flavourings and Processing Aids), 2017. Safety of benzophenone to be used as flavouring. EFSA Journal 2017;15(11):5013, 33 pp. https://doi.org/10.2903/j. efsa.2017.5013

EFSA FAF Panel (EFSA Panel on Food Additives and Flavourings), Younes M, Aquilina G, Castle L, Engel K-H, Fowler P, Frutos Fernandez MJ, Fürst P, Gundert-Remy U, Gürtler R, Husøy T, Moldeus P, Oskarsson A, Shah R, Waalkens-Berendsen I, Wölfle D, Benigni R, Bolognesi C, Chipman K, Cordelli E, Degen G, Marzin D, Svendsen C, Carfí M, Vianello G and Mennes W, 2019. Scientific Opinion on Flavouring Group Evaluation 215 Revision 1 (FGE.215Rev1): seven $\alpha, \beta$-unsaturated cinnamyl ketones from subgroup 3.2 of FGE.19. EFSA Journal 2019;17 (11):5875, 34 pp. https://doi.org/doi:10.2903/j.efsa.2019.5875

EFSA FEEDAP Panel (EFSA Panel on Additives and Products or Substances used in Animal Feed), 2012a. Guidance for the preparation of dossiers for sensory additives. EFSA Journal 2012;10(1):2534, 26 pp. https://doi.org/doi: 10.2903/j.efsa.2012.2534

EFSA FEEDAP Panel (EFSA Panel on Additives and Products or Substances used in Animal Feed), 2012b. Guidance for the preparation of dossiers for additives already authorised for use in food. EFSA Journal 2012;10(1):2538, 4 pp. https://doi.org/doi:10.2903/j.efsa.2012.2538

EFSA FEEDAP Panel (EFSA Panel on Additives and Products or Substances used in Animal Feed), 2012c. Guidance for establishing the safety of additives for the consumer. EFSA Journal 2012;10(1):2537, 12 pp. https://doi. org/doi:10.2903/j.efsa.2012.2537

EFSA FEEDAP Panel (EFSA Panel on Additives and Products or Substances used in Animal Feed), 2012d. Guidance on studies concerning the safety of use of the additive for users/workers. EFSA Journal 2012;10(1):2539, 5 pp. https://doi.org/doi:10.2903/j.efsa.2012.2539

EFSA FEEDAP Panel (EFSA Panel on Additives and Products or Substances used in Animal Feed), 2016. Safety and efficacy of aromatic ketones, secondary alcohols and related esters belonging to chemical group 21 when used as flavourings for all animal species. EFSA Journal 2016;14(8):4557, 17 pp. https://doi.org/doi:10.2903/j.efsa. 2016.4557

FAO, 2006. FAO JECFA Monographs 1: Combined Compendium of Food Additive Specifications - Joint FAO/WHO Expert Committee on Food Additives - All specifications monographs from the 1st to the 65th meeting (19562005). Volume 4. Analytical methods, test procedures and laboratory solutions used by and referenced in the food additive specifications. Food and Agricultural Organization of the United Nations, Rome. Available online: http://www.fao.org/docrep/009/a0691e/a0691e00.htm

IARC, 2013. Benzophenone. IARC Monographs on the Evaluation of Carcinogenic Risks to Humans, 101, $285-304$.

NTP (National Toxicology Program), 2006. NTP technical report on the toxicology and carcinogenesis studies of benzophenone (CAS no. 119-61-9) in F344/N rats and B6C3F1 mice (feed studies). February 2006. NTP TR 533. NIH Publication No. 06-4469.

WHO (World Health Organization), 2001. Evaluation of certain food additives and contaminants. Fifty-fifth report of the Joint FAO/WHO Expert Committee on Food Additives. WHO Technical Report Series, no. 901. Geneva, 615 June 2000.

WHO (World Health Organization), 2002. Evaluation of certain food additives and contaminants. Fifty-seventh report of the Joint FAO/WHO Expert Committee on Food Additives. WHO Technical Report Series, no. 909. Geneva, 5-14 June 2001. 


\section{Abbreviations}

CAS Chemical Abstracts Service

CDG chemically defined group

CEF EFSA Scientific Panel on Food Contact Materials, Enzymes, Flavourings and Processing Aids

CG chemical group

EURL European Union Reference Laboratory

FAO Food Agricultural Organisation

FEEDAP EFSA Scientific Panel on Additives and Products or Substances used in Animal Feed

FFAC Feed Flavourings authorisation Consortium of FEFANA (EU Association of Specialty Feed

FGE food group evaluation

FLAVIS The EU Flavour Information System

FL-No. FLAVIS number

GC-MS gas chromatography-mass spectrometry

HACCP hazard analysis and critical control points

JECFA The Joint FAO/WHO Expert Committee on Food Additives

Log Kow logarithm of octanol-water partition coefficient

NOAEL no observed adverse effect level

RTL Retention Time Locking

TTC threshold of toxicological concern

UF uncertainty factor

WHO World Health Organisation 


\section{Annex A - Executive Summary of the Evaluation Report of the European Union Reference Laboratory for Feed Additives on the Method(s) of Analysis for Aromatic ketones, secondary alcohols and related esters}

The Chemically Defined Flavourings - Group 21 (Aromatic ketones, secondary alcohols and related esters), in this application comprises ten substances, for which authorisation as feed additives is sought under the category 'sensory additives', functional group 2(b) 'flavouring compounds', according to the classification system of Annex I of Regulation (EC) No 1831/2003.

In the current application submitted according to Article 4(1) and Article 10(2) of Regulation (EC) No $1831 / 2003$, the authorisation for all species and categories is requested. The flavouring compounds of interest have a purity ranging from $95 \%$ to $99 \%$.

Mixtures of flavouring compounds are intended to be incorporated only into feedingstuffs or drinking water. The Applicant suggested no minimum or maximum levels for the different flavouring compounds in feedingstuffs.

For the identification of volatile chemically defined flavouring compounds CDG21 in the feed additive, the Applicant submitted a qualitative multi-analyte gas chromatography-mass spectrometry (GC-MS) method, using Retention Time Locking (RTL), which allows a close match of retention times on GC-MS. By making an adjustment to the inlet pressure, the retention times can be closely matched to those of a reference chromatogram. It is then possible to screen samples for the presence of target compounds using a mass spectral database of RTL spectra. The Applicant maintained two FLAVOR2 databases/libraries (for retention times and for MS spectra) containing data for more than 409 flavouring compounds. These libraries were provided to the EURL. The Applicant provided the typical chromatogram for the CDG21 of interest.

In order to demonstrate the transferability of the proposed analytical method (relevant for the method verification), the Applicant prepared a model mixture of flavouring compounds on a solid carrier to be identified by two independent expert laboratories. This mixture contained 20 chemically defined flavourings belonging to 20 different chemical groups to represent the whole spectrum of compounds in use as feed flavourings with respect to their volatility and polarity. Both laboratories properly identified all the flavouring compounds in all the formulations. Since the substances of CDG21 are within the volatility and polarity range of the model mixture tested, the Applicant concluded that the proposed analytical method is suitable to determine qualitatively the presence of the substances from CDG21 in the mixture of flavouring compounds.

Based on the satisfactory experimental evidence provided, the EURL recommends for official control for the qualitative identification in the feed additive of the individual (or mixture of) flavouring compounds of interest the GC-MS-RTL (Agilent specific) method submitted by the Applicant.

As no experimental data were provided by the Applicant for the identification of the active substance(s) in feedingstuffs and water, no methods could be evaluated. Therefore, the EURL is unable to recommend a method for the official control to identify the active substance(s) of interest in feedingstuffs or water. 